\title{
Existence and Iterative Approximation Methods for Generalized Mixed Vector Equilibrium Problems with Relaxed Monotone Mappings
}

\author{
Rabian Wangkeeree ${ }^{1,2}$ and Panu Yimmuang ${ }^{1}$ \\ ${ }^{1}$ Department of Mathematics, Faculty of Science, Naresuan University, Phitsanulok 65000, Thailand \\ ${ }^{2}$ Centre of Excellence in Mathematics, CHE, Si Ayutthaya Road, Bangkok 10400, Thailand \\ Correspondence should be addressed to Rabian Wangkeeree; rabianw@nu.ac.th
}

Received 22 March 2013; Revised 3 June 2013; Accepted 21 June 2013

Academic Editor: Filomena Cianciaruso

Copyright (C) 2013 R. Wangkeeree and P. Yimmuang. This is an open access article distributed under the Creative Commons Attribution License, which permits unrestricted use, distribution, and reproduction in any medium, provided the original work is properly cited.

\begin{abstract}
We first consider an auxiliary problem for the generalized mixed vector equilibrium problem with a relaxed monotone mapping and prove the existence and uniqueness of the solution for the auxiliary problem. We then introduce a new iterative scheme for approximating a common element of the set of solutions of a generalized mixed vector equilibrium problem with a relaxed monotone mapping and the set of common fixed points of a countable family of nonexpansive mappings. The results presented in this paper can be considered as a generalization of some known results due to Wang et al. (2010).
\end{abstract}

\section{Introduction}

Let $H$ be a real Hilbert space with inner product $\langle\cdot, \cdot\rangle$ and norm $\|\cdot\|$, respectively. Let $X$ be a nonempty closed convex subset of $H$. Let $\varphi: X \times X \rightarrow \mathbb{R}=(-\infty,+\infty)$ be a bifunction. The equilibrium problem $\operatorname{EP}(\varphi)$ is to find $x \in$ $X$ such that

$$
\varphi(x, y) \geq 0, \quad \forall y \in X .
$$

As pointed out by Blum and Oettli $[1], \operatorname{EP}(\varphi)$ provides a unified model of several problems, such as the optimization problem, fixed point problem, variational inequality, and complementarity problem.

A mapping $S: X \rightarrow H$ is called nonexpansive, if

$$
\|S z-S y\| \leq\|z-y\|, \quad \forall z, y \in X .
$$

We denote the set of all fixed points of $S$ by $F(S)$, that is, $F(S)=\{z \in X: z=S z\}$. It is well known that if $X \subset H$ is bounded, closed, convex and $S$ is a nonexpansive mapping of $X$ onto itself, then $F(S)$ is nonempty (see [2]). A mapping $T: C \rightarrow H$ is said to be relaxed $\eta-\alpha$ monotone if there exist a mapping $\eta: C \times C \rightarrow H$ and a function $\alpha: H \rightarrow \mathbb{R}$ positively homogeneous of degree $p$, that is, $\alpha(t z)=t^{p} \alpha(z)$ for all $t>0$ and $z \in H$ such that

$$
\langle T x-T y, \eta(x, y)\rangle \geq \alpha(x-y), \quad \forall x, y \in C,
$$

where $p>1$ is a constant; see [3]. In the case of $\eta(x, y)=$ $x-y$ for all $x, y \in C, T$ is said to be relaxed $\alpha$-monotone. In the case of $\eta(x, y)=x-y$ for all $x, y \in C$ and $\alpha(z)=k\|z\|^{p}$, where $p>1$ and $k>0, T$ is said to be $p$-monotone; see [4-6]. In fact, in this case, if $p=2$, then $T$ is a $k$-strongly monotone mapping. Moreover, every monotone mapping is relaxed $\eta-\alpha$ monotone with $\eta(x, y)=x-y$ for all $x, y \in C$ and $\alpha=0$.

In 2000, Moudafi [7] introduced an iterative scheme of finding the solution of nonexpansive mappings and proved a strong convergence theorem. Recently, Huang et al. [8] introduced the approximate method for solving the equilibrium problem and proved the strong convergence theorem.

Let $\varphi: X \times X \rightarrow \mathbb{R}$ be a bifunction and T, $A: X \rightarrow$ $H$ nonlinear mappings. In 2010, Wang et al. [9] introduced the following generalized mixed equilibrium problem with a relaxed monotone mapping. 
Find $z \in C$ such that

$$
\begin{aligned}
\varphi(z, y)+\langle T z, \eta(y, z)\rangle+\langle A z, y-z\rangle & \geq 0, \\
\forall y & \in C .
\end{aligned}
$$

Problem (4) is very general setting, and it includes special cases of Nash equilibrium problems, complementarity problems, fixed point problems, optimization problems, and variational inequalities (see, e.g., $[8,10-13]$ and the references therein). Moreover, Wang et al. [9] studied the existence of solutions for the proposed problem and introduced a new iterative scheme for finding a common element of the set of solutions of a generalized equilibrium problem with a relaxed monotone mapping and the set of common fixed points of a countable family of nonexpansive mappings in a Hilbert space.

It is well known that the vector equilibrium problem provides a unified model of several problems, for example, vector optimization, vector variational inequality, vector complementarity problem, and vector saddle point problem [14-16]. In recent years, the vector equilibrium problem has been intensively studied by many authors (see, e.g., [12, 14-19] and the references therein).

Recently, Li and Wang [18] first studied the viscosity approximation methods for strong vector equilibrium problems and fixed point problems. Very recently, Shan and Huang [20] studied the problem of finding a common element of the set of fixed points of a nonexpansive mapping, the set of solutions of the generalized mixed vector equilibrium problem, and the solution set of a variational inequality problem with a monotone Lipschitz continuous mapping in Hilbert spaces. They first introduced an auxiliary problem for the generalized mixed vector equilibrium problem and proved the existence and uniqueness of the solution for the auxiliary problem. Furthermore, they introduced an iterative scheme for finding a common element of the set of fixed points of a nonexpansive mapping, the set of solutions of the generalized mixed vector equilibrium problem, and the solution set of a variational inequality problem with a monotone Lipschitz continuous mapping.

Let $Y$ be a Hausdorff topological vector space, and, let $C$ be a closed, convex and pointed cone of $Y$ with int $C \neq \emptyset$. Let $\varphi: X \times X \rightarrow Y$ be a vector-valued bifunction. The strong vector equilibrium problem (for short, $\operatorname{SVEP}(\varphi)$ ) is to find $z \in X$ such that

$$
\varphi(z, y) \in C, \quad \forall y \in X
$$

and the weak vector equilibrium problem (for short, $\operatorname{WVEP}(\varphi))$ is to find $z \in X$ such that

$$
\varphi(z, y) \notin-\operatorname{int} C, \quad \forall y \in X .
$$

In this paper, inspired and motivated by the works mentioned previously, we consider the following generalized mixed vector equilibrium problem with a relaxed monotone mapping (for short, $\operatorname{GVEPR}(\varphi, T)$ ): find $z \in X$ such that

$$
\varphi(z, y)+e\langle T z, \eta(y, z)\rangle+e\langle A z, y-z\rangle \in C, \quad \forall y \in X,
$$

where $e \in \operatorname{int} C, \varphi: X \times X \rightarrow Y$, and $T, A: X \rightarrow$ $H$ are the mappings. The set of all solutions of the generalized mixed vector equilibrium problem with a relaxed monotone mapping is denoted by $\operatorname{SGVEPR}(\varphi, T)$, that is,

$$
\begin{gathered}
\operatorname{SGVEPR}(\varphi, T) \\
\qquad\{z \in X: \varphi(z, y)+e\langle T z, \eta(y, z)\rangle \\
+e\langle A z, y-z\rangle \in C, \forall y \in X\} .
\end{gathered}
$$

If $A=0$, we denote the set $\operatorname{ASGVEPR}(\varphi, T)$ by

$$
\begin{aligned}
& \operatorname{ASGVEPR}(\varphi, T) \\
& =\{z \in X: \varphi(z, y)+e\langle T z, \eta(y, z)\rangle \in C, \forall y \in X\} .
\end{aligned}
$$

Some special cases of the problem (7) are as follows.

(1) If $Y=\mathbb{R}, C=\mathbb{R}^{+}$, and $e=1$, then $\operatorname{GVEPR}(\varphi, T)$ (7) reduces to the generalized mixed equilibrium problem with a relaxed monotone mapping (4).

(2) If $T=0$ and $A=0$, then $\operatorname{GVEPR}(\varphi, T)$ (7) reduces to the classic vector equilibrium problem (5).

We consider the auxiliary problem of $\operatorname{GVEPR}(\varphi, T)$ and prove the existence and uniqueness of the solutions of auxiliary problem of $\operatorname{GVEPR}(\varphi, T)$ under some proper conditions. By using the result for the auxiliary problem, we introduce a new iterative scheme for finding a common element of the set of solutions of a generalized mixed vector equilibrium problem with a relaxed monotone mapping and the set of common fixed points of a countable family of nonexpansive mappings and then obtain a strong convergence theorem. The results presented in this paper improve and generalize some known results of Wang et al. [9].

\section{Preliminaries}

Let $A: X \rightarrow H$ be a $\lambda$-inverse-strongly monotone mapping of $H$. For all $z, y \in X$ and $k>0$, one has [21]

$$
\begin{aligned}
& \|(I-k A) z-(I-k A) y\|^{2} \\
& \quad \leq\|z-y\|^{2}+k(k-2 \lambda)\|A z-A y\|^{2} .
\end{aligned}
$$

Hence, if $k \in(0,2 \lambda)$, then $I-k A$ is a nonexpansive mapping of $X$ into $H$.

For each point $z \in H$, there exists a unique nearest point of $X$, denoted by $P_{X} z$, such that

$$
\left\|z-P_{X} z\right\| \leq\|z-y\|
$$

for all $y \in X$. Such a $P_{X}$ is called the metric projection from $H$ onto $X$. The well-known Browder's characterization of $P_{X}$ ensures that $P_{X}$ is a firmly nonexpansive mapping from $H$ onto $X$, that is,

$$
\begin{array}{r}
\left\|P_{X} z-P_{X} y\right\|^{2} \leq\left\langle P_{X} z-P_{X} y, z-y\right\rangle, \\
\forall z, y \in H .
\end{array}
$$


Further, we know that for any $z \in H$ and $x \in X, x=P_{X} z$ if and only if

$$
\langle z-x, x-y\rangle \geq 0, \quad \forall y \in X .
$$

Let $S$ be a nonexpansive mapping of $X$ into itself such that $F(S) \neq \emptyset$. Then we have

$$
\begin{array}{r}
\widehat{x} \in F(S) \Longleftrightarrow\|S x-x\|^{2} \leq 2\langle x-S x, x-\widehat{x}\rangle, \\
\forall x \in X,
\end{array}
$$

which is obtained directly from the following:

$$
\begin{aligned}
\| x & -\widehat{x} \|^{2} \\
& \geq\|S x-S \widehat{x}\|^{2}=\|S x-\widehat{x}\|^{2}=\|S x-x+(x-\widehat{x})\|^{2} \\
& =\|S x-x\|^{2}+\|x-\widehat{x}\|^{2}+2\langle S x-x, x-\widehat{x}\rangle .
\end{aligned}
$$

This inequality is a very useful characterization of $F(S)$. Observe what is more that it immediately yields that $\operatorname{Fix}(S)$ is a convex closed set.

Definition 1 (see $[6,22]$ ). Let $X$ and $Y$ be two Hausdorff topological vector spaces, $E$ a nonempty, convex, subset of $X$ and $C$ a closed, convex and pointed cone of $Y$ with $\operatorname{int} C \neq \emptyset$. Let $\theta$ be the zero point of $Y, \mathbb{U}(\theta)$ the neighborhood set of $\theta, \mathbb{U}\left(x_{0}\right)$ be the neighborhood set of $x_{0}$, and $f: E \rightarrow Y$ a mapping.

(1) If for any $V \in \mathbb{U}(\theta)$ in $Y$, and there exists $U \in \mathbb{U}\left(x_{0}\right)$ such that

$$
f(x) \in f\left(x_{0}\right)+V+C, \quad \forall x \in U \cap E,
$$

then $f$ is called upper $C$-continuous on $x_{0}$. If $f$ is upper $C$-continuous for all $x \in E$, then $f$ is called upper $C$-continuous on $E$.

(2) If for any $V \in \mathbb{U}(\theta)$ in $Y$, and there exists $U \in \mathbb{U}\left(x_{0}\right)$ such that

$$
f(x) \in f\left(x_{0}\right)+V-C, \quad \forall x \in U \cap E,
$$

then $f$ is called lower $C$-continuous on $x_{0}$. If $f$ is lower $C$-continuous for all $x \in E$, then $f$ is called lower $C$-continuous on $E$.

(3) $f$ is called $C$-continuous if $f$ is upper $C$-continuous and lower $C$-continuous.

(4) If for any $x, y \in E$ and $t \in[0,1]$, and the mapping $f$ satisfies

$$
\begin{aligned}
& f(x) \in f(t x+(1-t) y)+C \\
& \quad \text { or } f(y) \in f(t x+(1-t) y)+C,
\end{aligned}
$$

then $f$ is called proper $C$-quasiconvex.

(5) If for any $x_{1}, x_{2} \in E$ and $t \in[0,1]$, and the mapping $f$ satisfies

$$
t f\left(x_{1}\right)+(1-t) f\left(x_{2}\right) \in f\left(t x_{1}-(1-t) x_{2}\right)+C,
$$

then $f$ is called $C$-convex.
Lemma 2 (see [19]). Let $X$ and $Y$ be two real Hausdorff topological vector spaces, $E$ is a nonempty, compact, convex subset of $X$, and $C$ is a closed, convex, and pointed cone of $Y$. Assume that $f: E \times E \rightarrow Y$ and $\psi: E \rightarrow Y$ are two vector valued mappings. Suppose that $f$ and $\psi$ satisfy the following:

(i) $f(x, x) \in C$, for all $x \in E$;

(ii) $\psi$ is upper $C$-continuous on $E$;

(iii) $f(\cdot, y)$ is lower $C$-continuous for all $y \in E$;

(iv) $f(x, \cdot)+\psi(\cdot)$ is proper $C$-quasiconvex for all $x \in E$.

Then there exists a point $x \in E$ satisfying

$$
F(x, y) \in C \backslash\{0\}, \quad \forall y \in E,
$$

where

$$
F(x, y)=f(x, y)+\psi(y)-\psi(x), \quad \forall x, y \in E .
$$

Definition 3 (see [3]). Let $E$ be a Banach space with the dual space $E^{*}$ and let $K$ be a nonempty subset of $E$. Let $T: K \rightarrow$ $E^{*}$, and $\eta: K \times K \rightarrow E$ be two mappings. The mapping $T: K \rightarrow E^{*}$ is said to be $\eta$-hemicontinuous, if for any fixed $x, y \in K$, the function $f:[0,1] \rightarrow(-\infty, \infty)$ defined by

$$
f(t)=\langle T((1-t) x+t y), \eta(x, y)\rangle
$$

is continuous at $0^{+}$.

\section{The Existence of Solutions for the Generalized Mixed Vector Equilibrium Problem with a Relaxed Monotone Mapping}

For solving the generalized mixed vector equilibrium problem with a relaxed monotone mapping, we give the following assumptions. Let $H$ be a real Hilbert space with inner $\langle\cdot, \cdot\rangle$ and norm $\|\cdot\|$, respectively. Assume that $X \subseteq H$ is nonempty, compact, convex subset, $Y$ is real Hausdorff topological vector space, and $C \subseteq Y$ is a closed, convex, and pointed cone. Let $\varphi: X \times X \rightarrow Y, T: X \rightarrow H$ be two mappings. For any $x \in H$, define a mapping $\Phi_{x}: X \times X \rightarrow Y$ as follows:

$$
\begin{aligned}
\Phi_{x}(z, y)= & \varphi(z, y)+e\langle T z, \eta(y, z)\rangle \\
& +\frac{e}{r}\langle y-z, z-x\rangle,
\end{aligned}
$$

where $r$ is a positive number in $\mathbb{R}$ and $e \in C \backslash\{0\}$. Let $\Phi_{x}, \varphi$, and $T$ satisfy the following conditions:

$\left(A_{1}\right)$ for all $z \in X, \varphi(z, z)=\theta$;

$\left(A_{2}\right) \varphi$ is monotone, that is, $\varphi(z, y)+\varphi(y, z) \in-C$ for all $z, y \in X$

$\left(A_{3}\right) \varphi(\cdot, y)$ is $C$-continuous for all $y \in X$;

$\left(A_{4}\right) \varphi(z, \cdot)$ is $C$-convex, that is,

$t \varphi\left(z, y_{1}\right)+(1-t) \varphi\left(z, y_{2}\right) \in \varphi\left(z, t y_{1}+(1-t) y_{2}\right)+C$, $\forall z, y_{1}, y_{2} \in X, \forall t \in[0,1]$, 
$\left(A_{5}\right)$ for all $y \in X, z \mapsto\langle T z, \eta(y, z)\rangle$ is continuous, and for any $u, v \in X$,

$y \longmapsto\langle T u, \eta(y, v)\rangle$ is convex and lower semicontinuous;

$\left(A_{6}\right) \Phi_{x}(z, \cdot)$ is proper $C$-quasiconvex for all $z \in X$ and $x \in H$.

Remark 4. Let $Y=\mathbb{R}, C=\mathbb{R}^{+}$, and $e=1$. For any $y \in$ $X$, if $\varphi(\cdot, y)$ is upper semicontinuous and $z \mapsto\langle T z, \eta(y, z)\rangle$ is continuous, then $\Phi_{x}(\cdot, y)$ is lower $C$-continuous. In fact, since $\varphi(\cdot, y)$ is upper semicontinuous and $z \mapsto\langle T z, \eta(y, z)\rangle$ is continuous, for any $\epsilon>0$, there exists a $\delta>0$ such that, for all $z \in\left\{z \in X,\left\|z-z_{0}\right\|<\delta\right\}$, we have

$$
\Phi_{x}(z, y)<\Phi_{x}\left(z_{0}, y\right)+\epsilon,
$$

where $z_{0}$ is a point in $X$. This means that $\Phi_{x}(\cdot, y)$ is lower $C$-continuous.

Remark 5. Let $Y=\mathbb{R}, C=\mathbb{R}^{+}$and $e=1$. Assume that $\varphi(z, \cdot)$ is a convex mapping for all $z \in X$. Then for any $y_{1}, y_{2} \in X$ and $t \in[0,1]$, we have

$$
\begin{aligned}
\Phi_{x} & \left(z, t y_{1}+(1-t) y_{2}\right) \\
= & \varphi\left(z, t y_{1}+(1-t) y_{2}\right) \\
& +\left\langle T z, \eta\left(t y_{1}+(1-t) y_{2}, z\right)\right\rangle \\
& +\frac{1}{r}\left\langle t y_{1}+(1-t) y_{2}-z, z-x\right\rangle \\
\leq & t \varphi\left(z, y_{1}\right)+(1-t) \varphi\left(z, y_{2}\right) \\
& +t\left\langle T z, \eta\left(y_{1}, z\right)\right\rangle+(1-t)\left\langle T z, \eta\left(y_{2}, z\right)\right\rangle \\
& +\frac{t}{r}\left\langle y_{1}-z, z-x\right\rangle+\frac{1-t}{r}\left\langle y_{2}-z, z-x\right\rangle \\
= & t\left(\varphi\left(z, y_{1}\right)+\left\langle T z, \eta\left(y_{1}, z\right)\right\rangle+\frac{1}{r}\left\langle y_{1}-z, z-x\right\rangle\right) \\
& +(1-t)\left(\varphi\left(z, y_{2}\right)+\left\langle T z, \eta\left(y_{2}, z\right)\right\rangle\right. \\
& \left.\quad+\frac{1}{r}\left\langle y_{2}-z, z-x\right\rangle\right) \\
= & t \Phi_{x}\left(z, y_{1}\right)+(1-t) \Phi_{x}\left(z, y_{2}\right) \\
\leq & \max \left\{\Phi_{x}\left(z, y_{1}\right), \Phi_{x}\left(z, y_{2}\right)\right\}
\end{aligned}
$$

which implies that $\Phi_{x}(z, \cdot)$ is proper $C$-quasiconvex.

Now we are in the position to state and prove the existence of solutions for the generalized mixed vector equilibrium problem with a relaxed monotone mapping.

Theorem 6. Let $X$ be a nonempty, compact, convex subset of a real Hilbert space $H$. Let $C$ be a closed, convex, and pointed cone of a Hausdorff topological vector space $Y$. Let $T: X \rightarrow H$ be an $\eta$-hemicontinuous and relaxed $\eta$ - $\alpha$-monotone mapping. Let $\varphi: X \times X \rightarrow Y$ be a vector-valued bifunction. Suppose that all the conditions $\left(A_{1}\right)-\left(A_{6}\right)$ are satisfied. Let $r>0$ and define a mapping $B_{r}: H \rightarrow X$ as follows:

$$
\begin{array}{r}
B_{r}(x)=\{z \in X: \varphi(z, y)+e\langle T z, \eta(y, z)\rangle \\
\left.+\frac{e}{r}\langle y-z, z-x\rangle \in C, \forall y \in X\right\}
\end{array}
$$

for all $x \in H$. Assume that

(i) $\eta(x, y)+\eta(y, x)=0$, for all $x, y \in X$;

(ii) for any $x, y \in X, \alpha(x-y)+\alpha(y-x) \geq 0$.

Then, the following holds.

(1) $B_{r}(z) \neq \emptyset$ for all $z \in X$.

(2) $B_{r}$ is single-value.

(3) $B_{r}$ is a firmly nonexpansive mapping, that is, for all $x, y \in X$,

$$
\left\|B_{r} x-B_{r} y\right\|^{2} \leq\left\langle B_{r} x-B_{r} y, x-y\right\rangle,
$$

(4) $F\left(B_{r}\right)=\operatorname{ASGVEPR}(\varphi, T)$,

(5) $\operatorname{ASGVEPR}(\varphi, T)$ is closed and convex.

Proof. (1) In Lemma 2, let $f(z, y)=\Phi_{x}(z, y)$, and, let $\psi(z)=$ $\theta$ for all $z, y \in X$ and $x \in H$. Then it is easy to check that $f$ and $\Phi$ satisfy all the conditions of Lemma 2. Thus, there exists a point $z \in X$ such that

$$
f(z, y)+\psi(z)-\psi(y) \in C, \quad \forall y \in X, x \in H,
$$

which gives that, for any $x \in H$,

$$
\varphi(z, y)+e\langle T z, \eta(y, z)\rangle+\frac{e}{r}\langle y-z, z-x\rangle \in C, \quad \forall y \in X .
$$

Therefor we conclude that $B_{r}(x) \neq \emptyset$ for all $x \in H$.

(2) For $x \in H$ and $r>0$, let $z_{1}, z_{2} \in B_{r}(x)$. Then

$$
\begin{aligned}
\varphi\left(z_{1}, y\right)+e\left\langle T z_{1}, \eta\left(y, z_{1}\right)\right\rangle \\
+\frac{e}{r}\left\langle y-z_{1}, z_{1}-x\right\rangle \in C, \quad \forall y \in X, \\
\varphi\left(z_{2}, y\right)+e\left\langle T z_{2}, \eta\left(y, z_{2}\right)\right\rangle \\
+\frac{e}{r}\left\langle y-z_{2}, z_{2}-x\right\rangle \in C, \quad \forall y \in X .
\end{aligned}
$$

Letting $y=z_{2}$ in (32) and $y=z_{1}$ in (33), adding (32) and (33), we have

$$
\begin{gathered}
\varphi\left(z_{2}, z_{1}\right)+\varphi\left(z_{1}, z_{2}\right)+e\left\langle T z_{1}-T z_{2}, \eta\left(z_{2}, z_{1}\right)\right\rangle \\
+\frac{e}{r}\left\langle z_{1}-z_{2}, z_{2}-z_{1}\right\rangle \in C .
\end{gathered}
$$


By the monotonicity of $\varphi$, we have

$$
e\left\langle T z_{1}-T z_{2}, \eta\left(z_{2}, z_{1}\right)\right\rangle+\frac{e}{r}\left\langle z_{1}-z_{2}, z_{2}-z_{1}\right\rangle \in C .
$$

Thus

$$
\frac{e}{r}\left\langle z_{1}-z_{2}, z_{2}-z_{1}\right\rangle-e\left\langle T z_{2}-T z_{1}, \eta\left(z_{2}, z_{1}\right)\right\rangle \in C .
$$

Since $T$ is relaxed $\eta$ - $\alpha$-monotone and $r>0$ and the property of $C$, one has

$$
e\left\langle z_{1}-z_{2}, z_{2}-z_{1}\right\rangle-\operatorname{er} \alpha\left(z_{2}-z_{1}\right) \in C .
$$

In (36) exchanging the position of $z_{1}$ and $z_{2}$, we get

$$
\frac{e}{r}\left\langle z_{2}-z_{1}, z_{1}-z_{2}\right\rangle-e \alpha\left(z_{1}-z_{2}\right) \in C
$$

that is,

$$
e\left\langle z_{2}-z_{1}, z_{1}-z_{2}\right\rangle-\operatorname{er} \alpha\left(z_{1}-z_{2}\right) \in C .
$$

Now, adding the inequalities (37) and (39),

$$
\begin{aligned}
& e\left\langle z_{1}-z_{2}, z_{2}-z_{1}\right\rangle-\operatorname{er} \alpha\left(z_{2}-z_{1}\right) \\
& \quad+e\left\langle z_{2}-z_{1}, z_{1}-z_{2}\right\rangle-\operatorname{er} \alpha\left(z_{1}-z_{2}\right) \in C .
\end{aligned}
$$

By using (iv), we have

$$
2 e\left\langle z_{2}-z_{1}, z_{1}-z_{2}\right\rangle \in C .
$$

If $\left\langle z_{2}-z_{1}, z_{1}-z_{2}\right\rangle<0$, then

$$
-2\left\langle z_{2}-z_{1}, z_{1}-z_{2}\right\rangle>0 .
$$

This implies that

$$
-2 e\left\langle z_{2}-z_{1}, z_{1}-z_{2}\right\rangle \in C
$$

From (41) and (43), we have $z_{1}=z_{2}$ which is a contradiction. Thus

$$
\left\langle z_{2}-z_{1}, z_{1}-z_{2}\right\rangle \geq 0
$$

so

$$
-\left\|z_{1}-z_{2}\right\|^{2}=\left\langle z_{1}-z_{2}, z_{2}-z_{1}\right\rangle \geq 0 .
$$

Hence $z_{1}=z_{2}$. Therefore $B_{r}$ is single value. Then

(3) For any $x_{1}, x_{2} \in H$, let $z_{1}=B_{r}\left(x_{1}\right)$ and $z_{2}=B_{r}\left(x_{2}\right)$.

$$
\begin{aligned}
& \varphi\left(z_{1}, y\right)+e\left\langle T z_{1}, \eta\left(y, z_{1}\right)\right\rangle \\
& +\frac{e}{r}\left\langle y-z_{1}, z_{1}-x_{1}\right\rangle \in C, \quad \forall y \in X, \\
& \varphi\left(z_{2}, y\right)+e\left\langle T z_{2}, \eta\left(y, z_{2}\right)\right\rangle \\
& +\frac{e}{r}\left\langle y-z_{2}, z_{2}-x_{2}\right\rangle \in C, \quad \forall y \in X .
\end{aligned}
$$

Letting $y=z_{2}$ in (46) and $y=z_{1}$ in (47), adding (46) and (47), we have

$$
\begin{aligned}
& \varphi\left(z_{1}, z_{2}\right)+\varphi\left(z_{2}, z_{1}\right)+e\left\langle T z_{1}, \eta\left(z_{2}, z_{1}\right)\right\rangle \\
& +e\left\langle T z_{2}, \eta\left(z_{1}, z_{2}\right)\right\rangle \\
& \quad+\frac{e}{r}\left\langle z_{2}-z_{1}, z_{1}-z_{2}-\left(x_{1}-x_{2}\right)\right\rangle \in C .
\end{aligned}
$$

Since $\varphi$ is monotone and $C$ is closed convex cone, we get

$$
\begin{aligned}
& \left\langle T z_{1}-T z_{2}, \eta\left(z_{2}, z_{1}\right)\right\rangle \\
& +\frac{1}{r}\left\langle z_{2}-z_{1}, z_{1}-z_{2}-x_{1}+x_{2}\right\rangle \geq 0,
\end{aligned}
$$

that is,

$$
\begin{aligned}
& \frac{1}{r}\left\langle z_{2}-z_{1}, z_{1}-z_{2}-x_{1}+x_{2}\right\rangle \\
& \quad \geq\left\langle T z_{2}-T z_{1}, \eta\left(z_{2}, z_{1}\right)\right\rangle \\
& \quad \geq \alpha\left(z_{2}-z_{1}\right) .
\end{aligned}
$$

In (50) exchanging the position of $z_{1}$ and $z_{2}$, we get

$$
\begin{aligned}
& \frac{1}{r}\left\langle z_{1}-z_{2}, z_{2}-z_{1}-x_{2}+x_{1}\right\rangle \\
& \quad \geq \alpha\left(z_{1}-z_{2}\right) .
\end{aligned}
$$

Adding the inequalities (50) and (51), we have

$$
\begin{aligned}
& 2\left\langle z_{1}-z_{2}, z_{2}-z_{1}-x_{2}+x_{1}\right\rangle \\
& \quad \geq r\left(\alpha\left(z_{1}-z_{2}\right)+\alpha\left(z_{2}-z_{1}\right)\right) .
\end{aligned}
$$

It follows from (iv) that

$$
\left\langle z_{1}-z_{2}, z_{2}-z_{1}-x_{2}+x_{1}\right\rangle \geq 0 .
$$

This implies that

$$
\left\|B_{r} x_{1}-B_{r} x_{2}\right\|^{2} \leq\left\langle B_{r} x_{1}-B_{r} x_{2}, x_{1}-x_{2}\right\rangle .
$$

This shows that $B_{r}$ is firmly nonexpansive.

(4) We claim that $F\left(B_{r}\right)=\operatorname{ASGVEPR}(\varphi, T)$. Indeed, we have the following:

$$
\begin{aligned}
x \in F\left(B_{r}\right) & \Longleftrightarrow x=B_{r} x \\
& \Longleftrightarrow \varphi(x, y)+e\langle T x, \eta(y, x)\rangle \\
& +\frac{e}{r}\langle y-x, x-x\rangle \in C, \quad \forall y \in X \\
& \Longleftrightarrow \varphi(x, y)+e\langle T x, \eta(y, x)\rangle \in C, \quad \forall y \in X \\
& \Longleftrightarrow x \in \operatorname{ASGVEPR}(\varphi, T) .
\end{aligned}
$$

(5) Since every firmly nonexpansive mapping is nonexpansive, we see that $B_{r}$ is nonexpansive. Since the set of fixed point of every nonexpansive mapping is closed and convex, we have that $\operatorname{ASGVEPR}(\varphi, T)$ is closed and convex. This completes the proof. 


\section{Convergence Analysis}

In this section, we prove a strong convergence theorem which is one of our main results.

Theorem 7. Let $X$ be a nonempty, compact, convex subset of a real Hilbert space $H$. Let $C$ be a closed, convex cone of a real Hausdorff topological vector space $Y$ and $e \in C \backslash\{0\}$. Let $\varphi: X \times X \rightarrow Y$ satisfy $\left(A_{1}\right)-\left(A_{6}\right)$. Let $T: X \rightarrow H$ be an $\eta$-hemicontinuous and relaxed $\eta-\alpha$-monotone mapping. Let $A: X \rightarrow H$ be a $\lambda$-inverse-strongly monotone mapping, and let $\left\{S_{n}\right\}_{n=1}^{\infty}$ be a countable family of nonexpansive mappings from $X$ onto itself such that

$$
F:=\cap_{n=1}^{\infty} \operatorname{Fix}\left(S_{n}\right) \cap \operatorname{SGVEPR}(\varphi, T) \neq \emptyset .
$$

Assume that the conditions (i)-(ii) of Theorem 6 are satisfied. Put $\alpha_{0}=1$ and assume that $\left\{\alpha_{n}\right\}_{n=1}^{\infty} \subset(0,1)$ is a strictly decreasing sequence. Assume that $\left\{\beta_{n}\right\}_{n=1}^{\infty} \subset(c, d)$ with some $c, d \in(0,1)$ and $\left\{\lambda_{n}\right\}_{n=1}^{\infty} \subset[a, b]$ with some $a, b \in(0,2 \lambda)$. Then, for any $x_{1} \in X$, the sequence $\left\{x_{n}\right\}$, generated by

$$
\begin{gathered}
\varphi\left(u_{n}, y\right)+e\left\langle T u_{n}, \eta\left(y, u_{n}\right)\right\rangle+e\left\langle A x_{n}, y-u_{n}\right\rangle \\
+\frac{e}{\lambda_{n}}\left\langle y-u_{n}, u_{n}-x_{n}\right\rangle \in C, \quad \forall y \in X, \\
y_{n}=\alpha_{n} x_{n}+\sum_{i=1}^{n}\left(\alpha_{i-1}-\alpha_{i}\right) \beta_{n} S_{i} x_{n} \\
+\left(1-\alpha_{n}\right)\left(1-\beta_{n}\right) u_{n}, \\
C_{n}=\left\{z \in X:\left\|y_{n}-z\right\| \leq\left\|x_{n}-z\right\|\right\}, \\
D_{n}=\cap_{j=1}^{n} C_{j}, \\
x_{n+1}=P_{D_{n}} x_{1}, \quad n \geq 1,
\end{gathered}
$$

converges strongly to $x^{*} \in P_{F} x_{1}$. In particular, if $X$ contains the origin 0 and taking $x_{1}=0$, then the sequence $\left\{x_{n}\right\}$ generated by (57) converges strongly to the minimum norm element in $F$, that is $x^{*}=P_{F} 0$.

Proof. We divide the proof into several steps.

Step 1. We will show that $F$ is closed and convex, the sequence $\left\{x_{n}\right\}$ generated by (57) is well defined, and $F \subset D_{n}$, for all $n \geq$ 1 .

First, we prove that $F$ is closed and convex. It suffices to prove that $\operatorname{SGVEPR}(\varphi, T)$ is closed and convex. Indeed, it is easy to prove the conclusion by the following fact:

$$
\begin{aligned}
\forall p \in \operatorname{SGVEPR}(\varphi, T) \Longleftrightarrow & \varphi(p, y)+e\langle T p, \eta(y, p)\rangle \\
& +\frac{e}{\lambda_{n}}\left\langle y-p, \lambda_{n} A p\right\rangle \in C
\end{aligned}
$$$$
\forall y \in X
$$

$$
\begin{array}{r}
\Longleftrightarrow \varphi(p, y)+e\langle T p, \eta(y, p)\rangle+\frac{e}{\lambda_{n}} \\
\times\left\langle y-p, p-\left(p-\lambda_{n} A p\right)\right\rangle \in C \\
\forall y \in X \\
\Longleftrightarrow p=B_{\lambda_{n}}\left(I-\lambda_{n} A\right) p .
\end{array}
$$

This implies that

$$
\operatorname{SGVEPR}(\varphi, T)=\operatorname{Fix}\left[B_{\lambda_{n}}\left(I-\lambda_{n} A\right)\right] .
$$

Since $B_{\lambda_{n}}\left(I-\lambda_{n} A\right)$ is a nonexpansive mapping for $\lambda_{n}<$ $2 \lambda$ and the set of fixed points of a nonexpansive mapping is closed and convex, we have that $\operatorname{SGVEPR}(\varphi, T)$ is closed and convex.

Next, we prove that the sequence $\left\{x_{n}\right\}$ generated by (57) is well defined and $F \subset D_{n}$ for all $n \geq 1$. By Definition of $C_{n}$, for all $z \in X$, the inequality

$$
\left\|y_{n}-z\right\| \leq\left\|x_{n}-z\right\|
$$

is equivalent to

$$
\left\langle y_{n}-x_{n}, y_{n}+x_{n}\right\rangle-2\left\langle y_{n}-x_{n}, z\right\rangle \leq 0 .
$$

It is easy to see that $C_{n}$ is closed and convex for all $n \in \mathbb{N}$. Hence $D_{n}$ is closed and convex for all $n \in \mathbb{N}$. For any $p \in F$, and since $u_{n}=B_{\lambda_{n}}\left(x_{n}-\lambda_{n} A x_{n}\right)$ and $I-\lambda_{n} A$ is nonexpansive, we have

$$
\begin{aligned}
\left\|y_{n}-p\right\|= & \| \alpha_{n}\left(x_{n}-p\right)+\sum_{i=1}^{n}\left(\alpha_{i-1}-\alpha_{i}\right) \beta_{n}\left(S_{i} x_{n}-p\right) \\
& \quad+\left(1-\alpha_{n}\right)\left(1-\beta_{n}\right)\left(u_{n}-p\right) \| \\
\leq & \alpha_{n}\left\|x_{n}-p\right\|+\sum_{i=1}^{n}\left(\alpha_{i-1}-\alpha_{i}\right) \beta_{n}\left\|S_{i} x_{n}-p\right\| \\
& +\left(1-\alpha_{n}\right)\left(1-\beta_{n}\right)\left\|u_{n}-p\right\| \\
\leq & \alpha_{n}\left\|x_{n}-p\right\|+\sum_{i=1}^{n}\left(\alpha_{i-1}-\alpha_{i}\right) \beta_{n}\left\|x_{n}-p\right\| \\
& +\left(1-\alpha_{n}\right)\left(1-\beta_{n}\right) \\
& \times\left\|B_{\lambda_{n}}\left(x_{n}-\lambda_{n} A x_{n}\right)-B_{\lambda_{n}}\left(p-\lambda_{n} A p\right)\right\| \\
\leq & \alpha_{n}\left\|x_{n}-p\right\|+\left(1-\alpha_{n}\right) \beta_{n}\left\|x_{n}-p\right\| \\
& +\left(1-\alpha_{n}\right)\left(1-\beta_{n}\right) \\
& \times \\
\leq & \alpha_{n}\left\|\left(x_{n}-\lambda_{n} A x_{n}\right)-\left(p-\lambda_{n} A p\right)\right\| \\
& +\left(1-\alpha_{n}\right)\left(1-\beta_{n}\right)\left\|x_{n}-p\right\| \\
= & \left\|x_{n}-p\right\| .
\end{aligned}
$$


This implies that $F \subset C_{n}$ for all $n \in \mathbb{N}$. Hence $F \subset \cap_{j=1}^{n} C_{j}$. That is

$$
F \subset D_{n}, \quad \forall n \in \mathbb{N} \text {. }
$$

Since $D_{n}$ is nonempty closed convex, we get that the sequence $\left\{x_{n}\right\}$ is well defined. This completes the proof of Step 1 .

Step 2. We shall show that $\left\|x_{n+1}-x_{n}\right\| \rightarrow 0$ as $n \rightarrow \infty$ and there is $x^{*} \in C$ such that $\lim _{n \rightarrow \infty}\left\|x_{n}-x^{*}\right\|=0$.

It easy to see that $D_{n+1} \subset D_{n}$ for all $n \in \mathbb{N}$ from the construction of $D_{n}$. Hence

$$
x_{n+2}=P_{D_{n+1}} x_{1} \in D_{n+1} \subset D_{n} .
$$

Since $x_{n+1}=P_{D_{n}} x_{1}$, we have

$$
\left\|x_{n+1}-x_{1}\right\| \leq\left\|x_{n+2}-x_{1}\right\|
$$

for all $n \geq 1$. This implies that $\left\{\left\|x_{n}-x_{1}\right\|\right\}$ is increasing. Note that $C$ is bounded, we get that $\left\{\left\|x_{n}-x_{1}\right\|\right\}$ is bounded. This shows that $\lim _{n \rightarrow \infty}\left\|x_{n}-x_{1}\right\|$ exists.

Since $x_{n+1}=P_{D_{n}} x_{1}$ and $x_{m+1}=P_{D_{m}} x_{1} \in D_{m} \subset D_{n}$ for all $m \geq n$, we have

$$
\left\langle x_{n+1}-x_{1}, x_{m+1}-x_{n+1}\right\rangle \geq 0 .
$$

It follows from (66) that

$$
\begin{aligned}
\| x_{m+1}- & x_{n+1} \|^{2} \\
= & \left\|x_{m+1}-x_{1}-\left(x_{n+1}-x_{1}\right)\right\|^{2} \\
= & \left\|x_{m+1}-x_{1}\right\|^{2}+\left\|x_{n+1}-x_{1}\right\|^{2} \\
& -2\left\langle x_{m+1}-x_{1}, x_{n+1}-x_{1}\right\rangle \\
= & \left\|x_{m+1}-x_{1}\right\|^{2}+\left\|x_{n+1}-x_{1}\right\|^{2} \\
& -2\left\langle x_{n+1}-x_{1}, x_{m+1}-x_{n+1}+x_{n+1}-x_{1}\right\rangle \\
= & \left\|x_{m+1}-x_{1}\right\|^{2}+\left\|x_{n+1}-x_{1}\right\|^{2} \\
& -2\left\langle x_{n+1}-x_{1}, x_{m+1}-x_{n+1}\right\rangle \\
\leq & \left\|x_{m+1}-x_{1}\right\|^{2}-\left\|x_{n+1}-x_{1}\right\|^{2} .
\end{aligned}
$$

By taking $m=n+1$ in (67), we have

$$
\left\|x_{n+2}-x_{n+1}\right\|^{2} \leq\left\|x_{n+2}-x_{1}\right\|^{2}-\left\|x_{n+1}-x_{1}\right\|^{2} \text {. }
$$

Since the limits of $\left\|x_{n}-x_{1}\right\|$ exist, we get that

$$
\left\|x_{n+2}-x_{n+1}\right\| \longrightarrow 0, \quad \text { as } n \longrightarrow \infty .
$$

This implies that

$$
\lim _{n \rightarrow \infty}\left\|x_{n+1}-x_{n}\right\|=0 .
$$

Moreover, from (67), we also have

$$
\lim _{m, n \rightarrow \infty}\left\|x_{m+1}-x_{n+1}\right\|=0 .
$$

This shows that the sequence $\left\{x_{n}\right\}$ is a Cauchy sequence. Hence there is $x^{*} \in C$ such that

$$
x_{n} \longrightarrow x^{*} \in C, \quad \text { as } n \longrightarrow \infty .
$$

Step 3. We shall show that $\left\|x_{n}-u_{n}\right\| \rightarrow 0$ as $n \rightarrow \infty$.

Since $x_{n+1} \in C_{n}$ and $\lim _{n \rightarrow \infty}\left\|x_{n}-x_{n+1}\right\|=0$, we have

$$
\left\|y-x_{n+1}\right\| \leq\left\|x_{n}-x_{n+1}\right\| \longrightarrow 0 \text { as } n \longrightarrow \infty,
$$

and hence

$$
\left\|y_{n}-x_{n}\right\| \leq\left\|y_{n}-x_{n+1}\right\|+\left\|x_{n}-x_{n+1}\right\| \longrightarrow 0 \text { as } n \longrightarrow \infty \text {. }
$$

Note that $u_{n}$ can be rewritten as $u_{n}=B_{\lambda_{n}}\left(x_{n}-\lambda_{n} A x_{n}\right)$ for all $n \geq 1$. We take $p \in F$ thus we have $p=B_{\lambda_{n}}\left(p-\lambda_{n} A p\right)$. Since $A$ is $\lambda$-inverse-strongly monotone, and $0<\lambda_{n}<2 \lambda$, we know that, for all $n \in \mathbb{N}$,

$$
\begin{aligned}
&\left\|u_{n}-p\right\|^{2} \\
&=\left\|B_{\lambda_{n}}\left(x_{n}-\lambda_{n} A x_{n}\right)-B_{\lambda_{n}}\left(p-\lambda_{n} A p\right)\right\|^{2} \\
& \leq\left\|x_{n}-\lambda_{n} A x_{n}-p+\lambda_{n} A p\right\|^{2} \\
&=\left\|\left(x_{n}-p\right)-\lambda_{n}\left(A x_{n}-A p\right)\right\|^{2} \\
&=\left\|x_{n}-p\right\|^{2}-2 \lambda_{n}\left\langle x_{n}-p, A x_{n}-A p\right\rangle \\
&+\lambda_{n}^{2}\left\|A x_{n}-A p\right\|^{2} \\
& \leq\left\|x_{n}-p\right\|^{2}-2 \lambda_{n} \lambda\left\|A x_{n}-A p\right\|^{2} \\
&+\lambda_{n}^{2}\left\|A x_{n}-A p\right\|^{2} \\
&=\left\|x_{n}-p\right\|^{2}+\lambda_{n}\left(\lambda_{n}-2 \lambda\right)\left\|A x_{n}-A p\right\|^{2} \\
& \leq\left\|x_{n}-p\right\|^{2} .
\end{aligned}
$$

Using (57) and (75), we have

$$
\begin{aligned}
& \left\|y_{n}-p\right\|^{2} \\
& =\| \alpha_{n}\left(x_{n}-p\right) \\
& \quad+\sum_{i=1}^{n}\left(\alpha_{i-1}-\alpha_{i}\right) \beta_{n}\left(S_{i} x_{n}-p\right) \\
& \quad+\left(1-\alpha_{n}\right)\left(1-\beta_{n}\right)\left(u_{n}-p\right) \|^{2} \\
& \leq \alpha_{n}\left\|x_{n}-p\right\|^{2} \\
& \quad+\sum_{i=1}^{n}\left(\alpha_{i-1}-\alpha_{i}\right) \beta_{n}\left\|S_{i} x_{n}-p\right\|^{2} \\
& +\left(1-\alpha_{n}\right)\left(1-\beta_{n}\right)\left\|u_{n}-p\right\|^{2}
\end{aligned}
$$




$$
\begin{aligned}
\leq & \alpha_{n}\left\|x_{n}-p\right\|^{2}+\sum_{i=1}^{n}\left(\alpha_{i-1}-\alpha_{i}\right) \beta_{n}\left\|x_{n}-p\right\|^{2} \\
& +\left(1-\alpha_{n}\right)\left(1-\beta_{n}\right) \\
& \times\left(\left\|x_{n}-p\right\|^{2}+\lambda_{n}\left(\lambda_{n}-2 \lambda\right)\left\|A x_{n}-A p\right\|^{2}\right) \\
= & \left\|x_{n}-p\right\|^{2}+\left(1-\alpha_{n}\right) \\
& \times\left(1-\beta_{n}\right) \lambda_{n}\left(\lambda_{n}-2 \lambda\right)\left\|A x_{n}-A p\right\|^{2},
\end{aligned}
$$

and hence

$$
\begin{aligned}
& \left(1-\alpha_{n}\right)(1-d) a(2 \lambda-b)\left\|A x_{n}-A p\right\|^{2} \\
& \quad \leq\left(1-\alpha_{n}\right)\left(1-\beta_{n}\right) \lambda_{n}\left(2 \lambda-\lambda_{n}\right)\left\|A x_{n}-A p\right\|^{2} \\
& \quad \leq\left\|x_{n}-p\right\|^{2}-\left\|y_{n}-p\right\|^{2} \\
& \quad \leq\left\|x_{n}-y_{n}\right\|\left(\left\|x_{n}-p\right\|+\left\|y_{n}-p\right\|\right) .
\end{aligned}
$$

Note that $\left\{x_{n}\right\}$ and $\left\{y_{n}\right\}$ are bounded, $\alpha_{n} \rightarrow 0$, and $x_{n}-$ $y_{n}$ converges to 0 , we get that

$$
\lim _{n \rightarrow \infty}\left\|A x_{n}-A p\right\| \longrightarrow 0
$$

Using Theorem 6, we have

$$
\begin{aligned}
\| u_{n}- & p \|^{2} \\
& =\left\|B_{\lambda_{n}}\left(x_{n}-\lambda_{n} A x_{n}\right)-B_{\lambda_{n}}\left(p-\lambda_{n} A p\right)\right\|^{2} \\
\leq & \left\langle x_{n}-\lambda_{n} A x_{n}-\left(p-\lambda_{n} A p\right), u_{n}-p\right\rangle \\
& =\frac{1}{2}\left(\left\|x_{n}-\lambda_{n} A x_{n}-\left(p-\lambda_{n} A p\right)\right\|^{2}+\left\|u_{n}-p\right\|^{2}\right. \\
& \left.\quad-\left\|x_{n}-\lambda_{n} A x_{n}-\left(p-\lambda_{n} A p\right)-\left(u_{n}-p\right)\right\|^{2}\right) \\
\leq & \frac{1}{2}\left(\left\|x_{n}-p\right\|^{2}+\left\|u_{n}-p\right\|^{2}\right. \\
& \left.\quad-\left\|x_{n}-u_{n}-\lambda_{n}\left(A x_{n}-A p\right)\right\|^{2}\right) \\
= & \frac{1}{2}\left(\left\|x_{n}-p\right\|^{2}+\left\|u_{n}-p\right\|^{2}-\left\|x_{n}-u_{n}\right\|^{2}\right. \\
\quad & \left.+2 \lambda_{n}\left\langle x_{n}-u_{n}, A x_{n}-A p\right\rangle-\lambda_{n}^{2}\left\|A x_{n}-A p\right\|^{2}\right) .
\end{aligned}
$$

This implies that

$$
\begin{aligned}
\| u_{n}- & p \|^{2} \\
\leq & \left\|x_{n}-p\right\|^{2}-\left\|x_{n}-u_{n}\right\|^{2} \\
& +2 \lambda_{n}\left\langle x_{n}-u_{n}, A x_{n}-A p\right\rangle-\lambda_{n}^{2}\left\|A x_{n}-A p\right\|^{2} .
\end{aligned}
$$

From (80), we have

$$
\begin{aligned}
\left\|y_{n}-p\right\|^{2} & \| \alpha_{n}\left(x_{n}-p\right)+\sum_{i=1}^{n}\left(\alpha_{i-1}-\alpha_{i}\right) \beta_{n}\left(S_{i} x_{n}-p\right) \\
& +\left(1-\alpha_{n}\right)\left(1-\beta_{n}\right)\left(u_{n}-p\right) \|^{2} \\
\leq & \alpha_{n}\left\|x_{n}-p\right\|^{2}+\sum_{i=1}^{n}\left(\alpha_{i-1}-\alpha_{i}\right) \beta_{n}\left\|S_{i} x_{n}-p\right\|^{2} \\
& +\left(1-\alpha_{n}\right)\left(1-\beta_{n}\right)\left\|u_{n}-p\right\|^{2} \\
\leq & \alpha_{n}\left\|x_{n}-p\right\|^{2}+\left(1-\alpha_{n}\right) \beta_{n}\left\|x_{n}-p\right\|^{2} \\
& +\left(1-\alpha_{n}\right)\left(1-\beta_{n}\right) \\
& \times\left(\left\|x_{n}-p\right\|^{2}-\left\|x_{n}-u_{n}\right\|^{2}\right. \\
& \left.\quad+2 \lambda_{n}\left\langle x_{n}-u_{n}, A x_{n}-A p\right\rangle-\lambda_{n}^{2}\left\|A x_{n}-A p\right\|^{2}\right) \\
\leq & \left\|x_{n}-p\right\|^{2}-\left(1-\alpha_{n}\right)\left(1-\beta_{n}\right)\left\|x_{n}-u_{n}\right\|^{2} \\
& +2\left(1-\alpha_{n}\right)\left(1-\beta_{n}\right) \lambda_{n}\left\langle x_{n}-u_{n}, A x_{n}-A p\right\rangle,
\end{aligned}
$$

and hence

$$
\begin{aligned}
&(1-d)\left(1-\alpha_{n}\right)\left\|x_{n}-u_{n}\right\|^{2} \\
& \leq\left(1-\beta_{n}\right)\left(1-\alpha_{n}\right)\left\|x_{n}-u_{n}\right\|^{2} \\
& \leq\left\|x_{n}-y_{n}\right\|\left(\left\|x_{n}-p\right\|+\left\|y_{n}-p\right\|\right) \\
&+2\left(1-\alpha_{n}\right)\left(1-\beta_{n}\right) \lambda_{n} \\
& \times\left\|x_{n}-u_{n}\right\|\left\|A x_{n}-A_{p}\right\| .
\end{aligned}
$$

From (78) and $\lim _{n \rightarrow \infty}\left\|x_{n}-y_{n}\right\|=0$, we have

$$
\lim _{n \rightarrow \infty}\left\|x_{n}-u_{n}\right\|=0 \text {. }
$$

Step 4. We show that $\lim _{n \rightarrow \infty}\left\|x_{n}-S_{i} x_{n}\right\|=0$, for all $i=$ $0,1, \ldots$..

It follows from definition of scheme (57) that

$$
\begin{aligned}
y_{n} & +\sum_{i=1}^{n}\left(\alpha_{i-1}-\alpha_{i}\right) \beta_{n}\left(x_{n}-S_{i} x_{n}\right)-\left(1-\alpha_{n}\right) \beta_{n} x_{n} \\
& =\alpha_{n} x_{n}+\left(1-\alpha_{n}\right)\left(1-\beta_{n}\right) u_{n}
\end{aligned}
$$

that is,

$$
\begin{aligned}
& \sum_{i=1}^{n}\left(\alpha_{i-1}-\alpha_{i}\right) \beta_{n}\left(x_{n}-S_{i} x_{n}\right) \\
& =x_{n}-y_{n}-x_{n}+\alpha_{n} x_{n}+\left(1-\alpha_{n}\right) \beta_{n} x_{n} \\
& \quad+\left(1-\alpha_{n}\right)\left(1-\beta_{n}\right) u_{n}
\end{aligned}
$$




$$
\begin{aligned}
= & x_{n}-y_{n}+\left(1-\alpha_{n}\right)\left(\beta_{n}-1\right) x_{n} \\
& +\left(1-\alpha_{n}\right)\left(1-\beta_{n}\right) u_{n} \\
= & x_{n}-y_{n}+\left(1-\alpha_{n}\right)\left(1-\beta_{n}\right)\left(u_{n}-x_{n}\right) .
\end{aligned}
$$

Hence, for any $p \in F$, one has

$$
\begin{aligned}
\sum_{i=1}^{n}\left(\alpha_{i-1}-\alpha_{i}\right) \beta_{n}\left\langle x_{n}-S_{i} x_{n}, x_{n}-p\right\rangle \\
=\left(1-\alpha_{n}\right)\left(1-\beta_{n}\right)\left\langle u_{n}-x_{n}, x_{n}-p\right\rangle \\
+\left\langle x_{n}-y_{n}, x_{n}-p\right\rangle .
\end{aligned}
$$

Since each $S_{i}$ is nonexpansive and by (36) we get that

$$
\left\|S_{i} x_{n}-x_{n}\right\|^{2} \leq\left\langle x_{n}-S_{i} x_{n}, x_{n}-p\right\rangle .
$$

Hence, combining this inequality with (86), we have

$$
\begin{aligned}
\frac{1}{2} \sum_{i=1}^{n} & \left(\alpha_{i-1}-\alpha_{i}\right) \beta_{n}\left\|S_{i} x_{n}-x_{n}\right\|^{2} \\
\leq & \left(1-\alpha_{n}\right)\left(1-\beta_{n}\right)\left\langle u_{n}-x_{n}, x_{n}-p\right\rangle \\
& +\left\langle x_{n}-y_{n}, x_{n}-p\right\rangle,
\end{aligned}
$$

that is,

$$
\begin{aligned}
\left\|S_{i} x_{n}-x_{n}\right\|^{2} \leq & \frac{2\left(1-\alpha_{n}\right)\left(1-\beta_{n}\right)}{\left(\alpha_{i-1}-\alpha_{i}\right) \beta_{n}}\left\langle u_{n}-x_{n}, x_{n}-p\right\rangle \\
& +\frac{2}{\left(\alpha_{i-1}-\alpha_{i}\right) \beta_{n}}\left\langle x_{n}-y_{n}, x_{n}-p\right\rangle \\
\leq & \frac{2\left(1-\alpha_{n}\right)\left(1-\beta_{n}\right)}{\left(\alpha_{i-1}-\alpha_{i}\right) \beta_{n}}\left\|u_{n}-x_{n}\right\|\left\|x_{n}-p\right\| \\
& +\frac{2}{\left(\alpha_{i-1}-\alpha_{i}\right) \beta_{n}}\left\|x_{n}-y_{n}\right\|\left\|x_{n}-p\right\| .
\end{aligned}
$$

Since $\left\|u_{n}-x_{n}\right\| \rightarrow 0$ and $\left\|x_{n}-y_{n}\right\| \rightarrow 0$, we have

$$
\lim _{n \rightarrow \infty}\left\|S_{i} x_{n}-x_{n}\right\|=0, \quad \forall i=1,2, \ldots .
$$

Step 5. We show that $x_{n} \rightarrow x^{*}=P_{F} x_{1}$.

First, we show that $x^{*} \in \cap_{i=1}^{\infty} \operatorname{Fix}\left(S_{i}\right)$. Since

$$
\lim _{n \rightarrow \infty} x_{n}=x^{*}, \quad \lim _{n \rightarrow \infty}\left\|S_{i} x_{n}-x_{n}\right\|=0,
$$

we have

$$
x^{*} \in \operatorname{Fix}\left(S_{i}\right) \quad \text { for each } i=1,2, \ldots \text {. }
$$

Hence $x^{*} \in \cap_{i=1}^{\infty} \operatorname{Fix}\left(S_{i}\right)$. Next, we show that $x^{*} \in$ $\operatorname{SGVEPR}(\varphi, T)$. Noting that $u_{n}=B_{\lambda_{n}}\left(x_{n}-\lambda_{n} A x_{n}\right)$, one obtains

$$
\begin{array}{r}
\varphi\left(u_{n}, y\right)+e\left\langle T u_{n}, \eta\left(y, u_{n}\right)\right\rangle \\
+e\left\langle A x_{n}, y-u_{n}\right\rangle+\frac{e}{\lambda_{n}}\left\langle y-u_{n}, u_{n}-x_{n}\right\rangle \in C, \\
\forall y \in X,
\end{array}
$$

which implies that

$$
\begin{aligned}
& 0 \in \varphi\left(y, u_{n}\right)-\left\{e\left\langle T u_{n}, \eta\left(y, u_{n}\right)\right\rangle\right. \\
&+e\left\langle A x_{n}, y-u_{n}\right\rangle \\
&+ \frac{e}{\lambda_{n}}\left\langle y-u_{n}, u_{n}-x_{n}\right\}+C, \\
& \forall y \in X .
\end{aligned}
$$

Put $v_{t}=t y+(1-t) x^{*}$, for all $t \in(0,1)$ and $y \in X$. Then, we have $v_{t} \in X$. So, from (95), we have

$$
\begin{aligned}
e\left\langle v_{t}\right. & \left.-u_{n}, A v_{t}\right\rangle \\
\epsilon & e\left\langle v_{t}-u_{n}, A v_{t}\right\rangle \\
& -e\left\langle v_{t}-u_{n}, A x_{n}\right\rangle-e\left\langle v_{t}-u_{n}, \frac{u_{n}-x_{n}}{\lambda_{n}}\right\rangle \\
& +\varphi\left(v_{t}, u_{n}\right)+e\left\langle T u_{n}, \eta\left(u_{n}, v_{t}\right)\right\rangle+C . \\
= & e\left\langle v_{t}-u_{n}, A v_{t}-A u_{n}\right\rangle \\
& +e\left\langle v_{t}-u_{n}, A u_{n}-A x_{n}\right\rangle \\
& -e\left\langle v_{t}-u_{n}, \frac{u_{n}-x_{n}}{\lambda_{n}}\right\rangle+\varphi\left(v_{t}, u_{n}\right) \\
& +e\left\langle T u_{n}, \eta\left(u_{n}, v_{t}\right)\right\rangle+C .
\end{aligned}
$$

Since $\left\|x_{n}-u_{n}\right\| \rightarrow 0$ and the properties of $T$, we have

$$
\begin{gathered}
\left\|A u_{n}-A x_{n}\right\| \longrightarrow 0, \\
\frac{u_{n}-x_{n}}{\lambda_{n}} \longrightarrow 0, \\
\left\langle v_{t}-u_{n}, A u_{n}-A x_{n}\right\rangle \longrightarrow 0 .
\end{gathered}
$$

From the monotonicity of $A$, we have

$$
\left\langle v_{t}-u_{n}, A v_{t}-A u_{n}\right\rangle \geq 0 .
$$

Thus

$$
e\left\langle v_{t}-u_{n}, A v_{t}-A u_{n}\right\rangle \in C .
$$

So, from (96)-(99) and $\eta$-hemicontinuity of $T$, we have

$$
e\left\langle v_{t}-x^{*}, A v_{t}\right\rangle \in \varphi\left(v_{t}, x^{*}\right)+e\left\langle T x^{*}, \eta\left(x^{*}, v_{t}\right)\right\rangle+C .
$$

Since $\varphi$ is $C$-convex, we have

$$
t \varphi\left(v_{t}, y\right)+(1-t) \varphi\left(v_{t}, x^{*}\right) \in \varphi\left(v_{t}, v_{t}\right)+C .
$$

Since for any $u, v \in X$, and the mapping $x \mapsto\langle T v, \eta(x, u)\rangle$ is convex, we have

$$
\begin{aligned}
\left\langle T x^{*}, \eta\left(v_{t}, v_{t}\right)\right\rangle \leq & t\left\langle T x^{*}, \eta\left(y, v_{t}\right)\right\rangle \\
& +(1-t)\left\langle T x^{*}, \eta\left(x^{*}, v_{t}\right)\right\rangle .
\end{aligned}
$$


This implies that

$$
\begin{aligned}
& e t\left\langle T x^{*}, \eta\left(y, v_{t}\right)\right\rangle+e(1-t)\left\langle T x^{*}, \eta\left(x^{*}, v_{t}\right)\right\rangle \\
& \in e\left\langle T x^{*}, \eta\left(v_{t}, v_{t}\right)\right\rangle+C .
\end{aligned}
$$

From (101) and (103), we get that

$$
\begin{aligned}
& t \varphi\left(v_{t}, y\right)+(1-t) \varphi\left(v_{t}, x^{*}\right) \\
& \quad+e t\left\langle T x^{*}, \eta\left(y, v_{t}\right)\right\rangle+e(1-t)\left\langle T x^{*}, \eta\left(x^{*}, v_{t}\right)\right\rangle \\
& \in e\left\langle T x^{*}, \eta\left(v_{t}, v_{t}\right)\right\rangle+\varphi\left(v_{t}, v_{t}\right)+C=C,
\end{aligned}
$$

which implies that

$$
\begin{aligned}
& -t\left(\varphi\left(v_{t}, y\right)+e\left\langle T x^{*}, \eta\left(y, v_{t}\right)\right\rangle\right) \\
& \quad-(1-t)\left(\varphi\left(v_{t}, x^{*}\right)+e\left\langle T x^{*}, \eta\left(x^{*}, v_{t}\right)\right\rangle\right) \in-C .
\end{aligned}
$$

From (100) and (105), we have

$$
\begin{aligned}
& -t\left(\varphi\left(v_{t}, y\right)+e\left\langle T x^{*}, \eta\left(y, v_{t}\right)\right\rangle\right) \\
& \quad \in(1-t)\left(\varphi\left(v_{t}, x^{*}\right)+e\left\langle T x^{*}, \eta\left(x^{*}, v_{t}\right)\right\rangle\right)-C \\
& \quad \in(1-t) e\left\langle v_{t}-x^{*}, A v_{t}\right\rangle-C .
\end{aligned}
$$

This implies that

$$
\begin{aligned}
& -t\left(\varphi\left(v_{t}, y\right)+e\left\langle T x^{*}, \eta\left(y, v_{t}\right)\right\rangle\right) \\
& -e(1-t) t\left\langle y-x^{*}, A v_{t}\right\rangle \in-C .
\end{aligned}
$$

It follows that

$$
\begin{aligned}
& \left(\varphi\left(v_{t}, y\right)+e\left\langle T x^{*}, \eta\left(y, v_{t}\right)\right\rangle\right) \\
& \quad+e(1-t)\left\langle y-x^{*}, A v_{t}\right\rangle \in C .
\end{aligned}
$$

As $t \rightarrow 0$, we obtain that for each $y \in X$,

$$
\begin{aligned}
& \left(\varphi\left(x^{*}, y\right)+e\left\langle T x^{*}, \eta\left(y, x^{*}\right)\right\rangle\right) \\
& \quad+e(1-t)\left\langle y-x^{*}, A x^{*}\right\rangle \in C .
\end{aligned}
$$

Hence $x^{*} \in \operatorname{SGVEPR}(\varphi, T)$. Finally, we prove that $x^{*}=P_{F} x$. From $x_{n+1}=P_{D_{n}} x$ and $F \subset D_{n}$, we have

$$
\left\langle x-x_{n+1}, x_{n+1}-v\right\rangle \geq 0, \quad \forall v \in F .
$$

Note that $\lim _{n \rightarrow \infty} x_{n}=x^{*}$; we take the limit in (110), and then we have

$$
\left\langle x-x^{*}, x^{*}-v\right\rangle \geq 0, \quad \forall v \in F .
$$

We see that $x^{*}=P_{F} x$ by (33). This completes the proof.

Remark 8. If $Y=\mathbb{R}, C=\mathbb{R}^{+}$, and $e=1$, then Theorem 7 extends and improves Theorem 3.1 of Wang et al. [9].

\section{Acknowledgments}

The authors would like to thank the Thailand Research Fund and "Centre of Excellence in Mathematics" under the Commission on Higher Education, Ministry of Education, Thailandm for financial support.

\section{References}

[1] E. Blum and W. Oettli, "From optimization and variational inequalities to equilibrium problems," The Mathematics Student, vol. 63, no. 1-4, pp. 123-145, 1994.

[2] W. Takahashi, Nonlinear Functional Analysis, Yokohama Publishers, Yokohama, Japan, 2000.

[3] Y. P. Fang and N. J. Huang, "Variational-like inequalities with generalized monotone mappings in Banach spaces," Journal of Optimization Theory and Applications, vol. 118, no. 2, pp. 327338, 2003.

[4] D. Goeleven and D. Motreanu, "Eigenvalue and dynamic problems for variational and hemivariational inequalities," Communications on Applied Nonlinear Analysis, vol. 3, no. 4, pp. 1-21, 1996.

[5] A. H. Siddiqi, Q. H. Ansari, and K. R. Kazmi, "On nonlinear variational inequalities," Indian Journal of Pure and Applied Mathematics, vol. 25, no. 9, pp. 969-973, 1994.

[6] R. U. Verma, "Nonlinear variational inequalities on convex subsets of Banach spaces," Applied Mathematics Letters, vol. 10, no. 4 , pp. 25-27, 1997.

[7] A. Moudafi, "Viscosity approximation methods for fixed-points problems," Journal of Mathematical Analysis and Applications, vol. 241, no. 1, pp. 46-55, 2000.

[8] N. J. Huang, H. Y. Lan, and K. L. Teo, "On the existence and convergence of approximate solutions for equilibrium problems in Banach spaces," Journal of Inequalities and Applications, vol. 2007, Article ID 17294, 14 pages, 2007.

[9] S. Wang, G. Marino, and F. Wang, "Strong convergence theorems for a generalized equilibrium problem with a relaxed monotone mapping and a countable family of nonexpansive mappings in a Hilbert space," Fixed Point Theory and Applications, vol. 2010, Article ID 230304, 22 pages, 2010.

[10] J. W. Peng and J. C. Yao, "A new hybrid-extragradient method for generalized mixed equilibrium problems, fixed point problems and variational inequality problems," Taiwanese Journal of Mathematics, vol. 12, no. 6, pp. 1401-1432, 2008.

[11] J. W. Peng and J. C. Yao, "Two extragradient methods for generalized mixed equilibrium problems, nonexpansive mappings and monotone mappings," Computers \& Mathematics with Applications, vol. 58, no. 7, pp. 1287-1301, 2009.

[12] J. Li, N. J. Huang, and J. K. Kim, “On implicit vector equilibrium problems," Journal of Mathematical Analysis and Applications, vol. 283, no. 2, pp. 501-512, 2003.

[13] S. Takahashi and W. Takahashi, "Viscosity approximation methods for equilibrium problems and fixed point problems in Hilbert spaces," Journal of Mathematical Analysis and Applications, vol. 331, no. 1, pp. 506-515, 2007.

[14] G. Y. Chen, X. Huang, and X. Yang, Vector Optimization: SetValued and Variational Analysis, vol. 541 of Lecture Notes in Economics and Mathematical Systems, Springer, Berlin, Germany, 2005.

[15] F. Giannessi, Ed., Vector Variational Inequalities and Vector Equilibrium, vol. 38 of Nonconvex Optimization and Its Applications, Kluwer Academic, Dordrecht, The Netherlands, 2000.

[16] D. T. Luc, Theory of Vector Optimization, vol. 319 of Lecture Notes in Economics and Mathematical Systems, Springer, Berlin, Germany, 1989.

[17] Q. H. Ansari and F. Flores-Bazán, "Recession methods for generalized vector equilibrium problems," Journal of Mathematical Analysis and Applications, vol. 321, no. 1, pp. 132-146, 2006. 
[18] Q. Y. Li and S. H. Wang, "Viscosity approximation methods for strong vector equilibrium problems and fixed point problems," Acta Analysis Functionalis Applicata, no. 2, pp. 183-192, 2012.

[19] X. H. Gong and H. M. Yue, "Existence of efficient solutions and strong solutions for vector equilibrium problems," Journal of Nanchang University, vol. 32, pp. 1-5, 2008.

[20] S. Q. Shan and N. J. Huang, "An iterative method for generalized mixed vector equilibrium problems and fixed point of nonexpansive mappings and variational inequalities," Taiwanese Journal of Mathematics, vol. 16, no. 5, pp. 1681-1705, 2012.

[21] H. Iiduka and W. Takahashi, "Strong convergence theorems for nonexpansive mappings and inverse-strongly monotone mappings," Nonlinear Analysis: Theory, Methods \& Applications, vol. 61, no. 3, pp. 341-350, 2005.

[22] N. X. Tan, "On the existence of solutions of quasivariational inclusion problems," Journal of Optimization Theory and Applications, vol. 123, no. 3, pp. 619-638, 2004. 


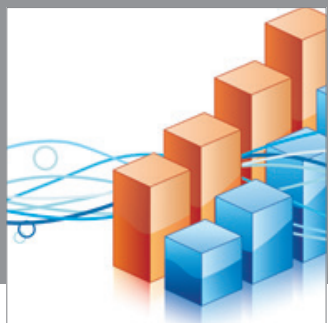

Advances in

Operations Research

mansans

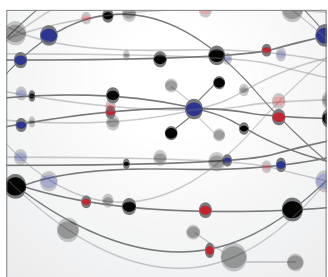

The Scientific World Journal
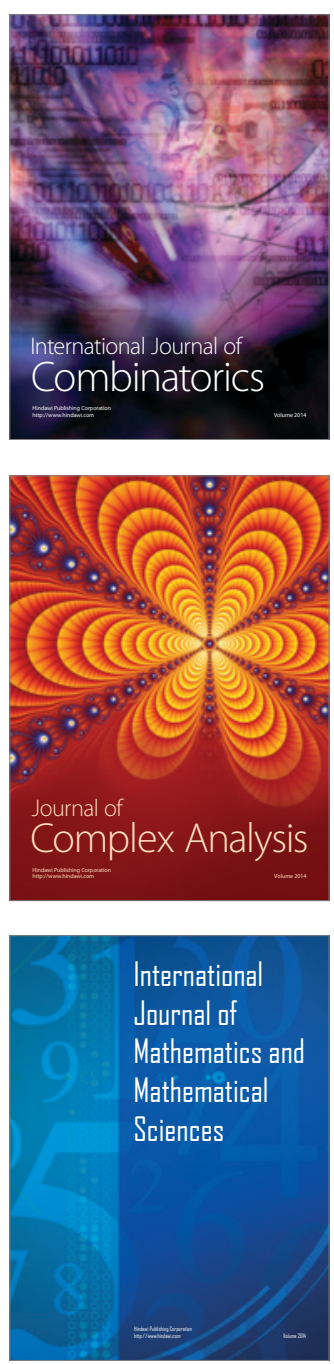
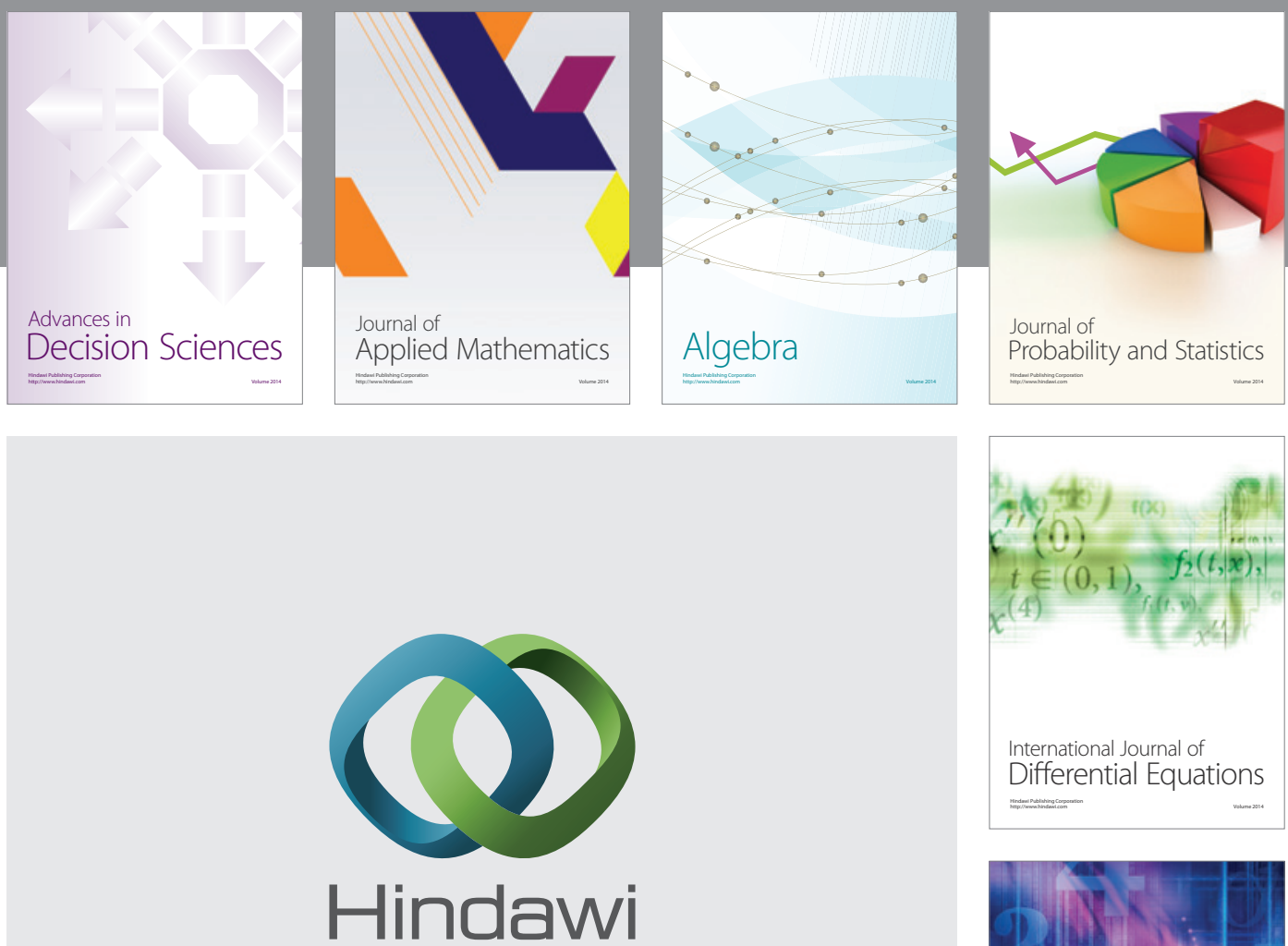

Submit your manuscripts at http://www.hindawi.com
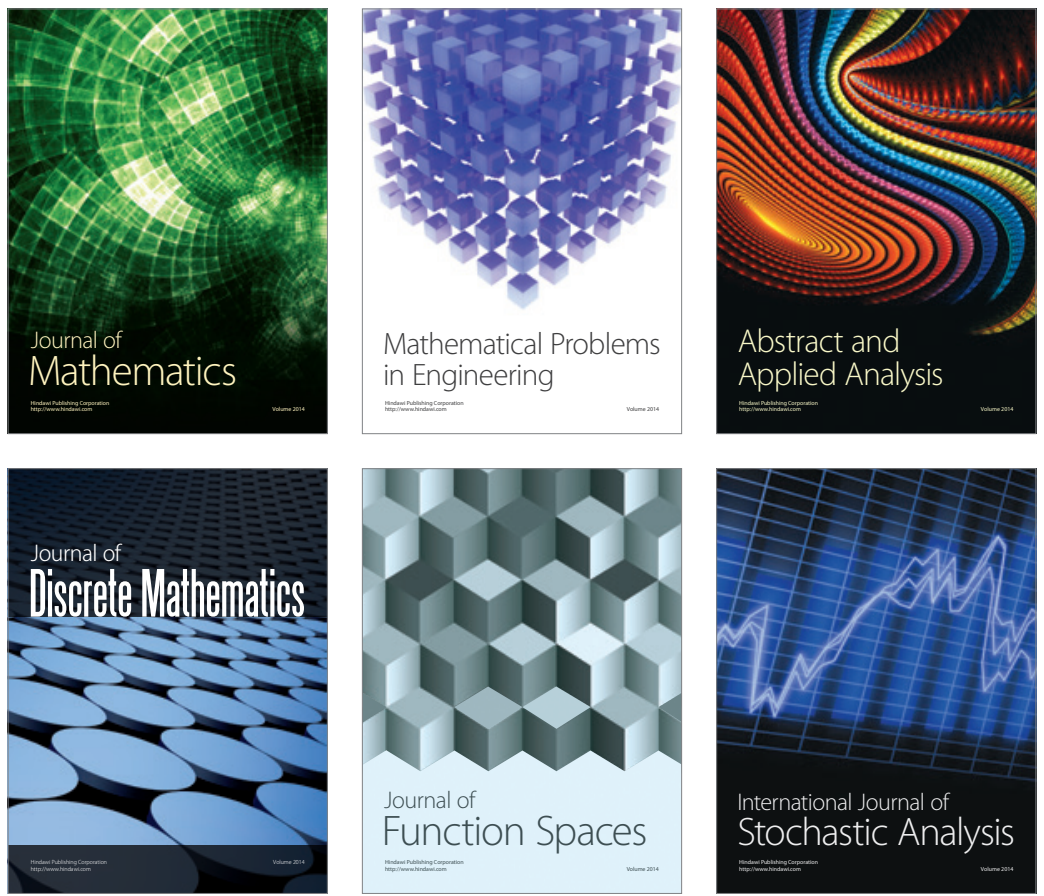

Journal of

Function Spaces

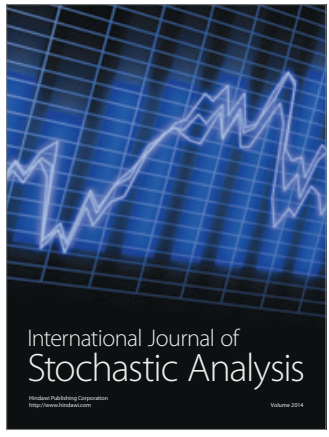

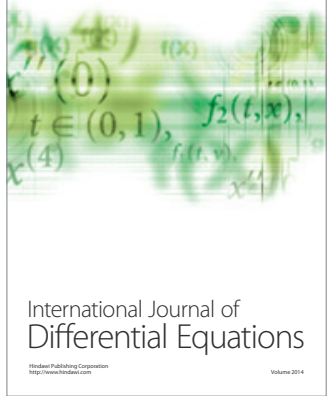
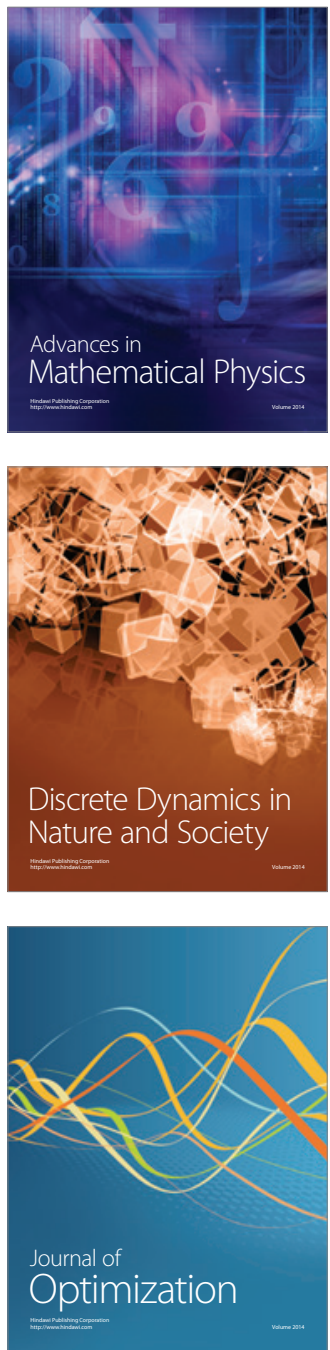